
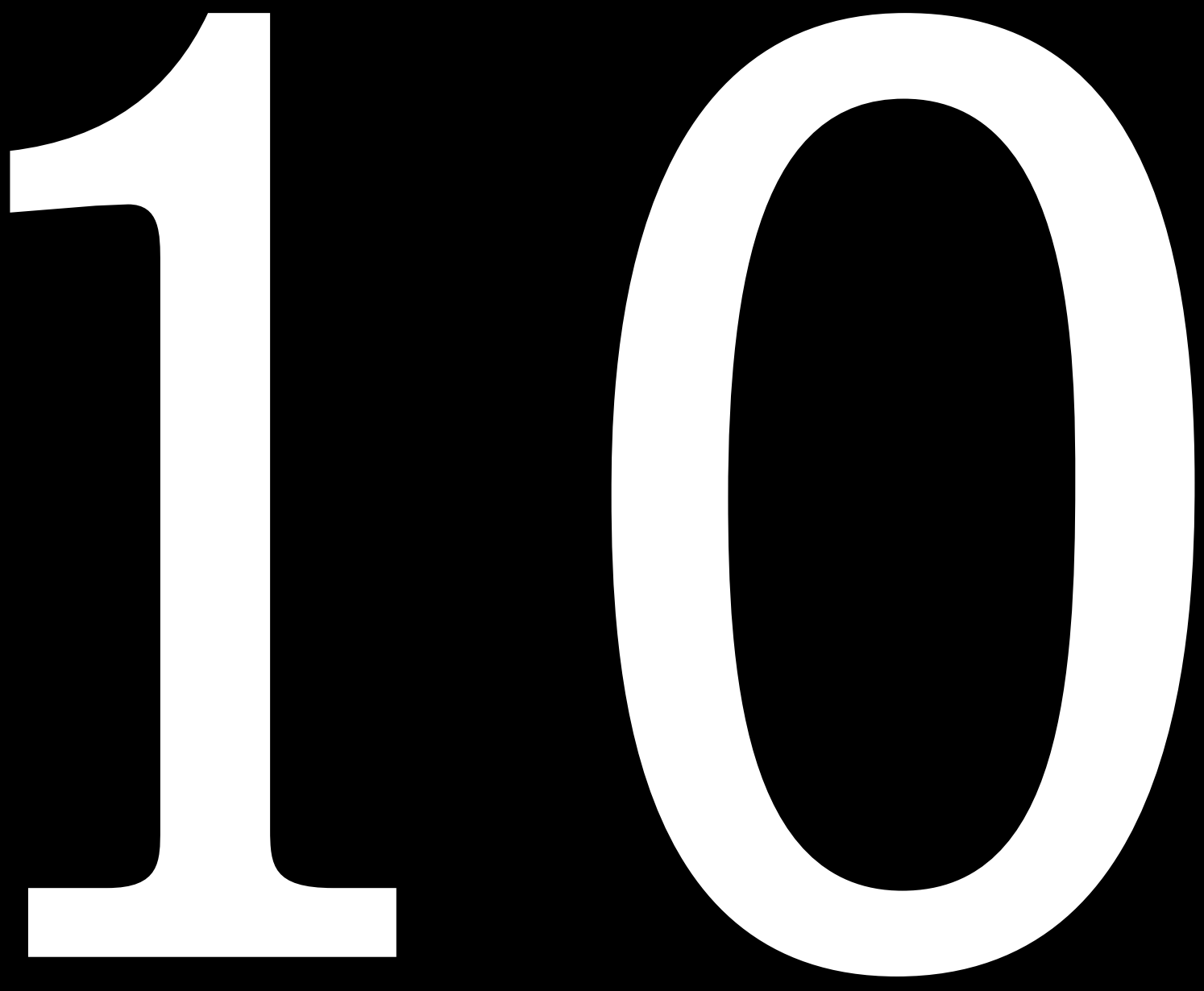

DOI: https://doi.org/10.14483/2422278X.16676 


\section{La paz no se rinde: crónicas y memorias de los acuerdos de La Habana ${ }^{1}$}

\section{Wilson Diaz Gamba ${ }^{2}$ \\ Jairo Andrés Hernández Cubides ${ }^{3}$}

Para citar: Díaz Gamba, W., \& Hernández Cubides, J. A. (2020). La paz no se rinde: crónicas y memorias de los acuerdos de La Habana. Ciudad Paz-ando, 12(1), 119-121. doi: https://doi.org/10.14483/2422278X.16676

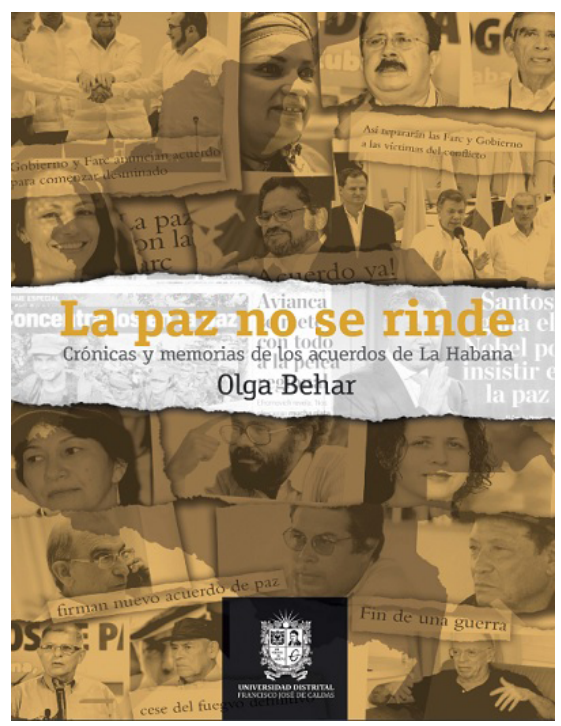

1 Behar, O. (2018). La paz no se rinde: crónicas y memorias de los acuerdos de La Habana. Bogotá: Universidad Distrital Francisco José de Caldas. 2 Licenciado en Ciencias Sociales, Psicólogo, Especialista en Desarrollo Humano y Procesos Afectivos, magíster en Investigación Social Interdisciplinaria. Director del Instituto de Paz (Ipazud) de la Universidad Distrital Francisco José de Caldas. Docente de la Maestría en Investigación Social Interdisciplinaria y del área de Humanidades de la Facultad de Ingeniería de la Universidad Distrital Francisco José de Caldas. Correo electrónico: wjdn50@yahoo.com,wdiazg@udistrital.edu.co

3 Administrador Público y Especialista en Derechos Humanos de la Escuela Superior de Administración Pública de Colombia. Estudiante de la Maestría en Derechos Humanos y Derecho Internacional de los Conflictos Armados de la Escuela Superior de Guerra "General Rafael Reyes Prieto". Investigador de la Línea Memoria y Conflicto del Instituto para la Pedagogía, la Paz y el Conflicto Urbano (Ipazud) de la Universidad Distrital Francisco José de Caldas. Correo electrónico: jahcubides@gmail.com 
El 21 de abril de 2018, en el marco de la Feria Internacional del Libro de Bogotá, la escritora, periodista y politóloga vallecaucana Olga Behar Leiser, hizo el lanzamiento oficial de su libro La paz no se rinde: crónicas y memorias de los acuerdos de La Habana, una obra escrita y producida en colaboración con su hija Carolina Ardila Behar y el Investigador Pablo Navarrete. Ese mismo día, el equipo de investigación del Instituto para la Pedagogía, la Paz y el Conflicto Urbano - Ipazud de la Universidad Distrital Francisco José de Caldas, realizó una entrevista a la autora posterior a su lanzamiento, que se encuentra en otro número de esta revista.

Una de las preguntas de dicho encuentro, indagaba sobre el porqué del título y a qué se hacia referencia con la afirmación de la paz no se rinde. Hoy, dos años después de aquel lanzamiento, ese mismo equipo de investigación ha decidido hacer una breve reseña de su última obra, en un intento de mantener vivo el recuerdo de lo que significó el acuerdo de paz firmado entre el Gobierno Nacional de Colombia y la desaparecida guerrilla de las Farc-Ep. Hemos tomado la decisión, de intentar explicar a través de nuestras palabras e ideas escritas, por qué la paz no se rinde.

La guerra en Colombia desde el sentido común pareciera ser un conflicto fratricida, que en palabras de Paul Valery, se suele explicar cómo "la masacre entre gente que no se conoce para el beneficio de gente que si se conoce pero que no se mata" (Artaud, 2005, pág. 56). Pero reducir el conflicto colombiano a una metáfora axiológica, es una lectura muy simplista, en tanto que es claro que las fuentes de conflicto y la violencia en el país surgen de lo que Johan Galtung (2003) denomina violencias estructurales: la pobreza, la marginación, la injusticia, la opresión, la explotación, la ignorancia y la intolerancia.

En Colombia la guerra, como lo muestra Juan Carlos Amador, uno de los autores del libro, es un legado macabro que recibimos desde comienzos de nuestra historia, razón por la cual, esta es narrada y aprendida a través de hechos de violencia, conflictos armados y violación al sentido de humanidad. Secuencia que se inició con la abrupta llegada de los españoles y el holocausto de su conquista, seguido por una imposición colonial que organizó las relaciones sociales sobre la desigualdad y la exclusión. En nuestro país pareciera que es la desconfianza en las instituciones, el odio, la intolerancia y intransigencia, las que nos identifican y estructuran nuestro comportamientos.

Es así, que si la guerra es la continuación de la política por otros medios como exclamo Carl Von Clausewitz (2014); de Colombia podría decirse que la guerra es la expresión de su cultura, y de ello dan cuenta las doce guerras civiles que se dieron a partir del grito de independencia de 1810 en el siglo XIX y las dos guerras civiles no declaradas durante el siglo XX e inicios del XXI, donde la constante pareciera ser, que sólo a partir de la eliminación del otro es que se refunda el orden y la paz.

Como lo recuerda Martha Nussbaum (2010), los odios no nacen, sino que son infundados; de la misma manera como se nos hereda el lenguaje, así mismo se configuran los odios o exclusiones, o ¿cuándo se ha visto a un niño con prejuicios o rencores que no hayan sido infundados? En Colombia, a la gran mayoría de los ciudadanos, se les ha enseñado a odiar desde que se nace y así como se le inscribe a las personas en una religión, también se les forma para odiar al otro, lo que ha generado que se sea menos fustigadores con las acciones de ciertos actores bélicos y más incisivos y críticos con otros.

Esta perspectiva de crear un enemigo natural, más que un rasgo cultural, es una construcción artificial en la que cada parte ejemplifica a la otra como la representación del mal, inculcando el odio hacia dicha representación, objetivizando y deshumanizando al objeto de odio, lo que permite ser más agresivos y beligerantes con el oponente, al despersonalizar al adversario. Por que una cosa es odiar al guerrillero, al paramilitar y otra es odiar a una persona, con un nombre una historia y un futuro.

En Colombia la guerra en las últimas décadas ha forjado mucha literatura, lo que llevó a que se generara todo un género sobre el sicariato y el narcotráfico, y a partir de esto, muchas personas cambiaron su percepción sobre personajes como Pablo Escobar, o Popeye. Carlos Castaño escribió un libro en el que presentaba su visión del conflicto y muchas personas entendieron y justificaron su actuar. En tanto que cada persona tiene una historia que, aunque no lo justifica, si le permite explicar su accionar.

El libro que hoy reseñamos desde el Ipazud, fue uno de los primeros efectos del acuerdo de paz entre las Farc y el Estado colombiano en 2016, las Farc han empezado a contarnos la versión de su historia. En tal sentido, Olga Behar nos presenta un excelentemente texto construido que le empieza a dar voz a las Farc, mostrándonos a unos seres humanos que, aunque han sido los actores principales de una guerra sanguinaria, también han estado buscando la paz desde el inicio. Nos muestra que los mostros a los que por tanto tiempo se les temió tienen un nombre, un rostro, una familia, tienen experiencias y expectativas, miedos y sueños al igual que cualquier colombiano.

El texto inicia con un excelente análisis del profesor de la Universidad Distrital Juan Carlos Amador entorno a las raíces del conflicto armado en Colombia, el fenómeno de las victimas y los desafíos que enfrentará la sociedad para poder implementar lo pactado en la Habana. El siguiente aparte es desarrollado por Darío Fajardo Montaña y genera una contextualización y análisis del estado actual del agro colombiano evidenciando que una paz estable y duradera, se alcanzará definitivamente si se logra la transformación de la Colombia rural y campesina.

Por su parte, Olga Behar y sus colaboradores, construye seis crónicas, mostrando una perspectiva del conflicto 
armado colombiano a partir de la voz de sus protagonistas y testigos, una investigación que aborda un espectro temporal amplio desde la visión de varias generaciones de excombatientes que comparten sus vivencias, tejiendo un dialogo entre estos, para así mostrar la otra visión de los hechos que hubo detrás de la noticia y que quedaron opacadas por el ruido de los fusiles y la guerra.

El libro en si, no es una reconstrucción historiográfica del conflicto, sino que retoma hechos memorables y los retoma a través de las personas que vivieron y estuvieron en el campo de batalla. Es un viaje a las entrañas de las Farc, a los hechos íntimos de la historia colombiana narrada desde la perspectiva humana y sentimental de quienes hicieron parte del suceso; configurando un árbol genealógico de las Farc y las relaciones intergeneracionales que se dieron dentro de estas, desnudando lo que significó para esta guerrilla las muertes de Jacobo Arenas, Raúl Reyes, Iván Ríos, Manuel Marulanda y el Mono Jojoy entre otros, evidenciando las solidaridades, los héroes, las leyendas y las lealtades que se construyeron al interior de una de las organizaciones guerrilleras que marcaron la historia de Colombia.

Se narran los detalles inéditos sobre los primeros contactos del gobierno Santos con esta guerrilla, las barreras, los obstáculos y las estrategias para superar los escollos que se presentaban para construir un lenguaje común de entendimiento, en donde la muerte de Alfonso Cano se convirtió en la cuota de sangre que tuvo que pagar la organización para asumir los diálogos.

Behar nos muestra la perspectiva del gobierno nacional a través de la visión del jefe negociador Humberto De La Calle. También se debela la lectura que tiene una periodista como Patricia Uribe quien por muchos años cubrió de forma rigurosa las acciones de las Farc. Así mismo, entrevista a Víctor G. Ricardo (primer alto comisionado para la paz en el Gobierno Pastrana) quien revelar hechos íntimos del proceso del Caguán y todo lo concerniente a la "silla vacía" y la no participación de Manuel Marulanda en la apertura de la negociación el 7 de enero de 1999.

Aborda la relación de las Farc con el narcotráfico, generando un excelente contexto histórico al retomar una entrevista a Jacobo Arenas en la revista semana y la visión que tiene Mauricio Jaramillo sobre el auge del narcotráfico en las zonas dominadas por esta guerrilla, así como la lectura que realiza Ariel Ávila sobre el factor económico del narcotráfico en el quehacer de la organización.

El libro proporciona una excelente crónica sobre las víctimas, exponiendo lo hechos en torno al secuestro de los diputados del Valle del Cauca y su posterior asesinato, a partir de varios testimonios tanto de las victimas como de los integrantes de las Farc que fueron protagonistas de los sucesos, y cierra con la descripción del encuentro entre victimas y victimarios, y las emociones suscitadas dentro de dicho proceso.

El cierre del texto se da con la visión de las mujeres al interior de las Farc, donde Sandra Ramírez, compañera sentimental de Manuel Marulanda, Victoria Sandino y Alexandra Nariño (Tanja) relatan sus historias de vida al interior de la organización y la evolución de las Farc en referencia a los temas de género.

En tal sentido, la paz no se rinde, es la constancia de que Colombia puede cambiar su destino, y el proceso de paz es una decisión histórica para generar un desarrollo distinto, en el que la resolución de los conflictos por medio de la violencia, se quede en el pasado, convirtiéndose este texto en un primer insumo para cambiar los imaginarios que se han configurado entorno al conflicto con las Farc, en tanto que la sociedad colombiana tiene el gran reto de comenzar a reescribir su historia después de la guerra, empezando a sanar sus rencores y exorcizar sus odios.

\section{Referencias}

Artaud, A. (2005). La libertad del espíritu. Leviatán.

Galtung, J. (2003). Paz por medios pacificos: paz y conflicto, desarrollo y civilización. Bakeaz.

Galeano, E. (1997). Ser como ellos. Tercer Mundo.

Nussbaum, M. C. (2010). Sin fines de lucro. Por qué la democracia necesita de las humanidades. Katz.

Von Clausewitz, C. (2014). Carl von Clausewitz: Historical and Political Writings. Princeton University Press. 